\title{
USER EXPERIENCE OF A STYLUS PEN THAT CAN PROVIDE THE TEXTURE OF PEN AND PAPER
}

\author{
J. Ahn ${ }^{1}$, K. Park ${ }^{1} \&$ K. Kim ${ }^{1 *}$
}

\section{ARTICLE INFO}

$\begin{array}{lr}\text { Article details } & \\ \text { Submitted by authors } & \text { 18 Oct } 2018 \\ \text { Accepted for publication } & \text { 3 Jul } 2019 \\ \text { Available online } & \text { 30 Aug } 2019\end{array}$

\section{Contact details}

Corresponding author

kyungdoh.kim@hongik.ac.kr

\section{Author affiliations}

1 Department of Industrial Engineering, Hongik University,

Seoul, Republic of Korea

DOI

http://dx.doi.org/10.7166/30-2-2078
There is a lot of investment in research on displaying texture through a stylus pen. However, little is known about the effect of a stylus pen that can provide the texture of pen and paper on user experience. This study investigated whether there is a change in user experience when using a stylus pen that can provide pen-andpaper texture compared with a typical stylus pen. Experiments involving writing and drawing tasks using three tools (a stylus pen that can provide pen-and-paper texture, a typical stylus pen, and analogue pen and paper) were conducted, and user experiences were compared. After a literature review that examined the factors affecting the experience of using a pen, the experiments were conducted to measure usability and emotions. We found little difference between the typical stylus pen and the stylus pen in providing texture in respect of completion time and amount of error. However, the stylus pen that can provide texture showed results closer to those of the analogue pen and paper, and better results than those of the typical stylus pen in respect of familiarity and overall satisfaction of the usability and emotional variables. Therefore, this study confirmed that user experience is improved when using a stylus pen that can provide the texture of pen and paper.

\section{OPSOMMING}

Daar is al baie belê en nagevors in die nabootsing van die pen-oppapier gevoel van 'n elektroniese stilus. Daar is egter weinige inligting beskikbaar oor die effek wat tekstuur op gebruikerservaring het. Hierdie studie ondersoek of daar ' $n$ verandering in gebruikerservaring is wanneer ' $n$ stilus met pen-op-papier terugvoer gebruik word teenoor ' $n$ tipiese stilus wat nie terugvoer aan die gebruiker lewer nie. Eksperimente wat skryf en teken-take insluit is met drie gereedskapstukke ('n stilus met pen-op-papier terugvoer, 'n tipiese stilus, en 'n konvensionele pen op papier) uitgevoer. Na 'n literatuurstudie van stapel gestuur is, is die eksperimente uitgevoer om die bruikbaarheid en subjektiewe terugvoer van die gebruiker te bepaal. Die resultate toon min verskil tussen 'n tipiese stilus en een met die pen-op-papier gevoel, beide in terme van die tyd om die take te voltooi en die aantal foute begaan. Die stilus met penop-papier terugvoer se vertoning was nader aan die van ' $\mathrm{n}$ tradisionele pen, asook beter subjektiewe terugvoer van die gebruiker in terme van vertroudheid en algehele bevrediging. Die gevolgtrekking is dus dat ' $\mathrm{n}$ stilus met pen-op-papier terugvoer gebruikerservaring verbeter.

Stylus pens, used as an assistant tool in electronic notebooks in the 1980 s, are now a major input tool for electronic devices with touch screens, such as smart phones and tablets. With the 
emergence of smart devices based on touch screens, an environment has been provided to use input tools such as a pen [1], and stylus pens are a replacement for text input [2] and graphics tools on such devices [3]. In addition, efforts are underway to enable the use of common stylus pens on a variety of devices through the standardisation of the stylus pen [4].

A stylus pen is derived from an analogue pen, so it is moving toward delivering a pen-like experience. Firstly, the thickness of the stylus pen tip is gradually decreasing. For example, the thickness of the stylus pen tip on the Samsung Galaxy Note 5 is $1.6 \mathrm{~mm}$, compared with $0.7 \mathrm{~mm}$ on the Galaxy Note 8. Moreover, the tip of Wacom's INTUOS creative stylus pen is noticeably smallerin the secondgeneration stylus. With a thinner tip, it is possible to control the stylus precisely - as if it were an analogue pen. Secondly, pressure sensitivity is increasing. In the Galaxy Note series, the stylus pressure level of the Galaxy Note 5 is 2048 steps, but in the Galaxy Note 8 it has doubled to 4096 steps. Pressure sensitivity is necessary to show the effect of pressing the analogue pen. Therefore, this increase in pressure sensitivity shows the development direction of the stylus toward something closer to the analogue pen. Thirdly, tilt recognition technology has been applied to the stylus pen. The tilt recognition function gives the effect of tilting the pen, which can produce a shading effect, depending on the degree of tilt. At present, Apple has patented tilt recognition, and the Apple pencil has it [5]. The tilt recognition function can provide the feeling of a pencil. Lastly, recently developed stylus pens use rubber instead of plastic. For example, the S Pen of the Galaxy Note 8 has a rubber pen tip, and Wacom has stylus products that use a rubber pen tip. Through these efforts, the feeling of friction that occurs when using an analogue pen can be felt to be similar to that when using the stylus pen.

Despite these efforts, a stylus pen has yet to deliver the experience of pen and paper [6]. Annett, Anderson, Bischof, and Gupth [7] conducted an experiment comparing the experience of using a stylus pen with that of using an analogue pen. They summarised the features that need to be considered for making stylus pens that provide an analogue-pen-like experience. The primary features are 'stylus accuracy', 'device latency', and 'unintended touch', and the secondary features are 'texture and aesthetics' and 'stroke beautification'. Regarding the primary features, these have been improved through several studies [8-11]. 'Stroke beautification' has also been gradually developed, and can be seen in actual applications $[12,13]$. The aesthetic of a stylus pen is difficult to determine in technical studies because it can be changed according to individual taste and current trend, but there have been many attempts at industrial sites. On the other hand, although studies on the texture of a stylus pen are actively conducted [14-18], they have not yet been applied to commercial products.

A stylus pen typically uses a vibrator to create texture $[14,16,18,19]$. When using an analogue pen, the vibrations occur on all axes of three-dimensional space. When one vibrator is used in a stylus pen, it vibrates in a unidirectional axis, so the vibrations in all directions must be synthesised on one axis [20]. Moreover, in order to display texture through a stylus pen, the texture must be rendered on a display [21]. In addition, pressure, tilt, and azimuth should be considered for natural stylus use behaviour [22]. This complex computing process is not an easy task because it requires minimal latency. Furthermore, after applying the texture function to a stylus pen, miniaturisation must also be considered [16,17]. Similarly, implementing the texture of pen and paper in a stylus pen is not easy, and requires a lot of effort.

A lot of investment is being made to realise the texture of a typical pen through stylus pens. Therefore, it is necessary to examine what user experience benefits can be gained from these efforts. After understanding the effect of improving the texture feature of a typical pen, it will be possible to determine the appropriate amount of investment needed to improve the texture feature of the stylus pen. Therefore, this study examines the changes in user experience when using a stylus pen that can provide the texture of pen and paper. In Section 2, we review related studies that attempted to display textures in stylus pens, and we set up hypotheses and seek research methods. In Section 3, the variables used in our experiments are selected, and the research methods related to the experimental design are described. Section 4 presents the experimental results. Section 5 discusses the analysed results. Finally, in Section 6, the contents of this study are summarised, in addition to discussing its limitations and directions for future research. 
Several studies have developed stylus pens that provide textures and have evaluated their usability. Studies that have examined whether the stylus pen that can provide texture improves performance in a particular task have measured the complete time and error rate of the total task $[17,18]$. On a tapping task that involved tapping a specific part of the display with a stylus pen, the stylus pen providing texture did not show a satisfactory difference compared with a typical stylus pen [18]. On the other hand, on drawing or dragging tasks that involved moving with a stylus pen while touching the display, the stylus pen providing texture was less time-consuming [18] or had better accuracy than a typical stylus pen [17]. Since texture is perceived through skin movements and changes [23], a stylus pen providing texture may have a greater effect in tasks with much movement between the stylus pen and the display, such as a drawing task, than in tasks with little movement between the two, such as a tapping task.

Writing and free drawing using a stylus pen has been considered in many studies $[16,17,19]$. Writing and drawing are the most common tasks performed using an analogue pen and paper, so they are best suited for stylus pens that provide textures. In a study evaluating usability in these tasks, subjective satisfaction with the use of a stylus pen developed by them was investigated. The majority of users who participated in the test showed a positive response [17].

However, to date, no study has been conducted on emotion, which is a factor of user experience. Understanding the changes in emotions that occur when displaying the texture of pen and paper through a stylus pen can provide a standard for comparison when evaluating the emotions of users when using stylus pens providing texture that will be developed in the future. Therefore, we reviewed studies on tactile-related emotional words and stylus-related emotional words to select the emotional evaluation variables of a stylus pen.

In a study on the perceptual dimension of the tactile texture, the perceptual dimension is composed of words expressing the four tactile senses of 'smooth/rough', 'thin/thick', 'uneven', and 'hard' [24]. In addition, 'comfortable' and 'appealing' were used as emotional variables in studies evaluating the usability of typical mobile stylus pens [25]. Finally, a previous study was conducted to find the emotional factors that affect users' satisfaction with an analogue pen. Five emotional factors - 'comfortable', 'precise', 'deep', 'natural', and 'refined' were found to increase satisfaction with the pen [26].

Overall, if a stylus pen providing texture is used instead of a typical stylus pen, a better performance effect will be achieved in drawing tasks. It will also provide increased user satisfaction in writing and drawing, and affect users' emotions. To confirm these hypotheses, this study measures performance in drawing tasks, and conducts a subjective evaluation of writing and drawing tasks.

\section{METHOD}

\subsection{Participants}

The experiment was conducted with students at Hongik University, Seoul, Republic of Korea, who had a lot of writing activities and faced no difficulty in using touch screen-based smart devices. A total of 27 participants were recruited through online and offline recruiting. Twenty of them were males and seven were females, with a mean age of 23.9 years $(S D=2.87)$. The experiment took no longer than 50 minutes, and an honorarium of $\$ 5$ (KRW 5,000) was provided to all participants.

\subsection{Tasks}

All participants performed three tasks. Task 1 was to write a given sentence in the same way (writing). Task 2 was to draw a given still life figure (drawing). Finally, Task 3 was to connect lines along given points (point connecting). In this task, an unfinished picture was presented to participants that was completed by connecting the points in numerical order. Participants were instructed to complete the picture as quickly as possible, with each line being as straight as possible. Figure 1 shows each task. 


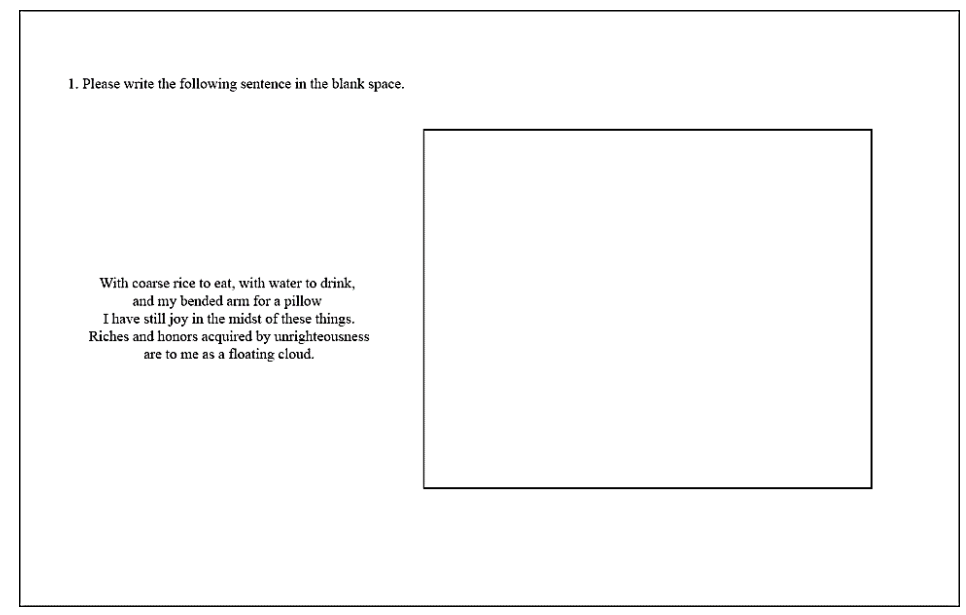

(a)

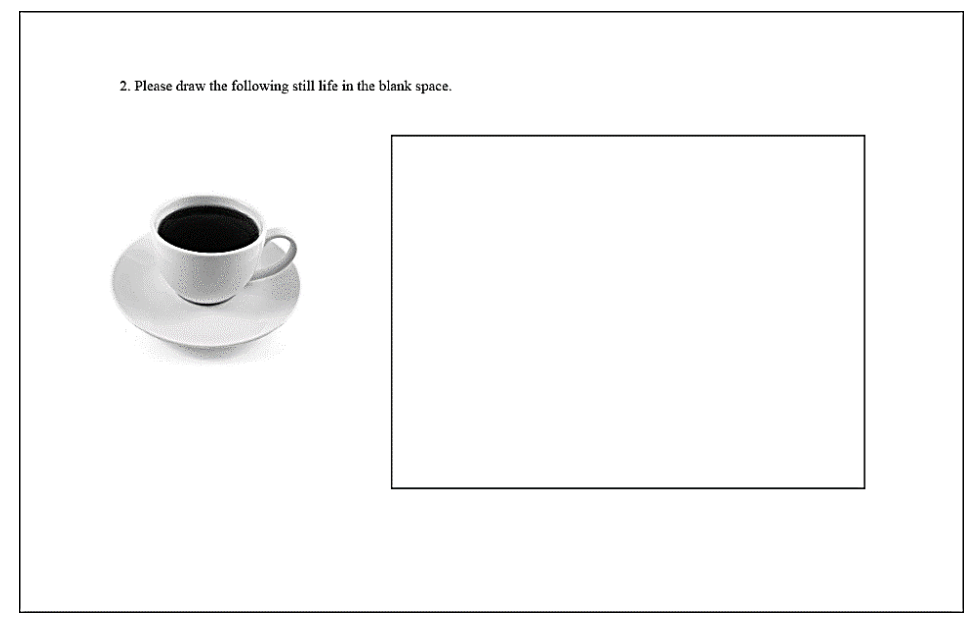

(b)

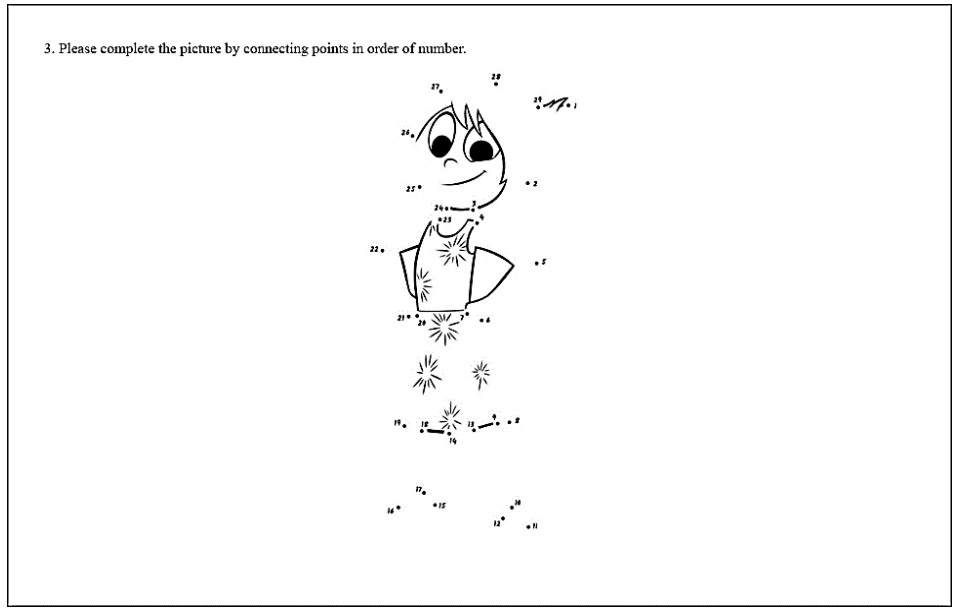

(c)

Figure 1: Images of the tasks: (a) Task 1 (writing task), (b) Task 2 (drawing task), (c) Task 3 (point connecting task) 


\subsection{Independent variable}

The independent variable, pen type, was designed at three levels: a typical stylus pen and tablet (hereinafter 'TS'), a modified stylus pen and paper that provides the texture of pen and paper (hereinafter 'MS'), and a typical ballpoint pen and paper (hereinafter 'PP'). Wacom INTUOS CTH480, a graphic tablet device, and Wacom INTUOS LP-180E, a stylus pen for this tablet device, were used for TS. MS was modified to provide the texture of an analogue pen by installing a ballpoint pen tip on the stylus pen. When using the MS, an A4-size page was placed on the tablet device. In this case, the tasks were performed on the paper placed on the tablet device, but the recognised handwriting appeared on the computer screen. Figure 2 shows the pens used in this study.

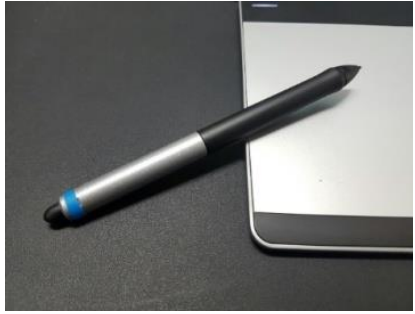

(a)

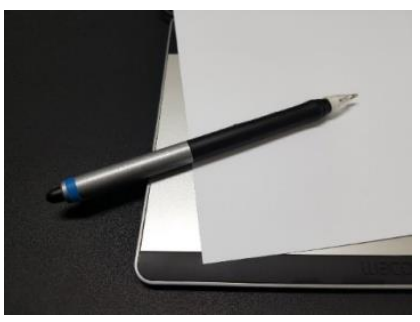

(b)

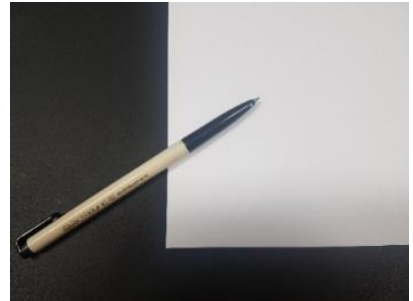

(c)

Figure 2: Images of the pens used in this study: (a) a typical stylus pen and tablet (TS), (b) a modified stylus pen and paper (MS), (c) a typical ballpoint pen and paper (PP)

\subsection{Dependent variables}

'Task completion time' and 'error amount' were selected as performance measures of usability variables. The two variables were measured through the point-connecting task only (Task 3 ) for only the two stylus pens (TS and MS). PP was excluded from Task 3 because of the difference between the image appearing on the display and the image being drawn on the paper.

'Task completion time' is the total time taken from the moment the initial point is touched to the moment the last point is linked. 'Error amount' is the size of the area in pixels where the drawn line deviates from the straight line connecting points (Figure 3). These variables were measured to examine whether our MS improves the efficiency and accuracy of the drawing task.

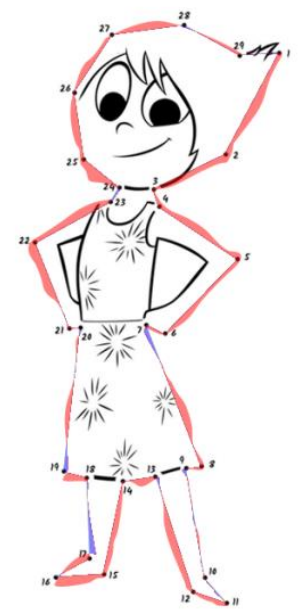

Figure 3: Example of error: red and blue areas are counted as error (see online version for colour)

'Familiarity' and 'overall satisfaction' were selected as subjective measures of usability variables. Familiarity was selected to check whether the stylus pen provides the familiar feel of an analogue pen. Overall satisfaction was used to examine whether the use of the pen was satisfactory. These two variables were measured for TS, MS, and PP in the writing task (Task 1) and the drawing task (Task 2). In order to measure familiarity, we asked participants whether they felt familiar when 
using this pen. The responses were rated on a seven-point Likert scale, with 1 being 'mostly disagree' and 7 being 'mostly agree'. Likewise, to measure overall satisfaction, participants were asked to provide their response on a seven-point Likert scale for the item 'I was satisfied when using this pen'.

'Emotions' refers to how users feel while using products. In order to select emotional variables, the existing stylus- and tactile-related research was reviewed. In Park, Del Pobil, and Kwon [25], 'comfortable' and 'appealing' were used as emotional variables. Further, in Picard, Dacremont, Valentin and Giboreau [24], four emotional variables were used: 'smooth/rough', 'thin/thick', 'uneven', and 'hard'. Additionally, 'comfortable', 'precise', 'deep', 'natural', and 'refined' were selected as emotional variables [26]. Among them, 'appealing' and 'refined', and 'thin/thick' and 'deep' were integrated. Subsequently, to make use of semantic differential measure, each variable was paired with antonyms. The selected emotional variables were as follows: 'uncomfortablecomfortable', which means how comfortable it is to use the pen, 'ordinary-appealing', which means how appealing it is to use the pen, 'smooth-rough', which refers to the smoothness of the pen, 'thinthick', which refers to the thickness of the pen, 'flat-uneven', which means how flat it is when using the pen, 'soft-hard', which means how hard it is when using the pen, 'crude-precise', which refers to the preciseness of the use of the pen, and 'awkward-natural', which means how natural it is to use the pen. As in subjective measures of usability variables, emotional variables were measured for TS, MS, and PP in the writing (Task 1) and drawing (Task 2) tasks. Emotional variables were designed based on a seven-point semantic differential scale. To summarise, subjective measures were collected from Tasks 1 and 2, while performance measures were obtained from Task 3 . The dependent variables used in this study are summarised in Table 1.

Table 1: Dependent variables

\begin{tabular}{|l|l|l|}
\hline \multicolumn{4}{|l|}{ Category } & Variables \\
\hline \multirow{4}{*}{ Usability } & $\begin{array}{l}\text { Performance } \\
\text { measures }\end{array}$ & Task completion time \\
\cline { 2 - 3 } & $\begin{array}{l}\text { Subjective } \\
\text { measures }\end{array}$ & Error amount \\
\hline \multirow{5}{*}{ Emotion } & Familiarity \\
\cline { 3 - 3 } & Overall satisfaction \\
\hline \multirow{5}{*}{} & Uncomfortable - Comfortable \\
\cline { 2 - 2 } & Ordinary - Appealing \\
\cline { 2 - 2 } & Smooth - Rough \\
\cline { 2 - 2 } & Thin - Thick \\
\cline { 2 - 2 } & Flat - Uneven \\
\cline { 2 - 2 } & Soft - Hard \\
\cline { 2 - 2 } & Crude - Precise \\
\cline { 2 - 2 } & Awkward - Natural \\
\hline
\end{tabular}

\subsection{Experimental environment}

The experiment was conducted in a controlled laboratory with enough light and minimal noise. Samsung DM700, a monitor-integrated computer, was used in the experiment, with the Wacom INTUOS CTH-480 connected. The apparatus was set on a flat desk so that participants could carry out their tasks by sitting in front of the desk.

\subsection{Experimental design and procedure}

An experiment moderator sat next to each participant and guided the experiment. All participants performed the tasks with all three pens (within subject design). The order of the pens was randomised, but counterbalanced. For each pen, participants performed the tasks in the following order: Tasks 1, 2, and 3. Before starting the tasks, participants were allowed to practise for five minutes with a dedicated pen to understand and familiarise themselves with how the pen worked. After completing each task (except Task 3), a questionnaire was provided to measure the subjective ratings of usability and emotional variables. Regarding Task 3, task completion time and error amount were measured. After completing all three tasks with one pen, a resting time of five minutes was given. 
A one-way ANOVA was performed for each dependent variable. Task completion time and error amount were measured in Task 3 only for TS and MS. The significance level was 0.05 .

\subsection{Usability}

For task completion time and error amount, a one-way ANOVA was conducted. There was no difference in task completion time between TS $(M=27.9 \mathrm{~s}, S D=14.39)$ and $M S(M=28.6 \mathrm{~s}, \mathrm{SD}=$ 11.15). Further, the difference in the amount of error between $T S(M=10,032.4$ pixels, $S D=$ $2,881.74)$ and $M S(M=10,144.4$ pixels, $S D=3,021.79)$ was not statistically significant. There were no differences between TS and MS in respect of performance aspects.

Familiarity and overall satisfaction were measured in TS, MS, and PP. A one-way ANOVA and a Tukey HSD test were conducted for each writing task and drawing task. There was a difference in familiarity and overall satisfaction in the writing task (Table 2). In the case of familiarity, scores were higher in the order of PP $(M=6.7, S D=.54), M S(M=4.4, S D=2.04)$, and $T S(M=3.3, S D=$ 1.73 ), and the difference among these pens was statistically significant (MS-TS, $p=.030$, PP-MS, $p$ $<.001$, PP-TS, $p<.001)$. In the case of overall satisfaction, the scores of PP $(M=5.7, S D=1.23)$ were higher than those of TS $(M=3.6, S D=1.43)$ and $M S(M=4.2, S D=1.67)(p s<.001)$, but there was no difference between TS and MS $(p=.130)$.

Table 2: Results of familiarity and overall satisfaction for one-way ANOVA and Tukey HSD tests in writing task

\begin{tabular}{|c|c|c|c|c|c|}
\hline \multirow{2}{*}{$\begin{array}{l}\text { Dependent } \\
\text { variables }\end{array}$} & \multicolumn{3}{|c|}{ Pen type } & \multirow{2}{*}{$F$} & \multirow{2}{*}{$p$-value } \\
\hline & MS & $T S$ & $P P$ & & \\
\hline \multirow{3}{*}{ Familiarity } & ${ }^{*} 4.4$ & 3.3 & & \multirow{3}{*}{32.82} & \multirow{3}{*}{$<.001$} \\
\hline & 4.4 & & *6.7 & & \\
\hline & & 3.3 & *6.7 & & \\
\hline \multirow{3}{*}{$\begin{array}{l}\text { Overall } \\
\text { satisfaction }\end{array}$} & 4.2 & 3.6 & & \multirow{3}{*}{13.89} & \multirow{3}{*}{$<.001$} \\
\hline & 4.2 & & *5.7 & & \\
\hline & & 3.6 & $* 5.7$ & & \\
\hline
\end{tabular}

Note: For significant $F$ ratios (bold font), * indicates which pen showed significantly higher score.

There were also statistical differences in familiarity and overall satisfaction in the drawing task (Table 3). In the case of familiarity, PP $(M=6.7, S D=.62)$ scores were higher than TS $(M=3.6$, SD $=1.63)$ and $M S(M=4.2, S D=1.99)(p s<.001)$. On the other hand, there was no significant difference between TS and MS ( $p=.249)$. In the case of overall satisfaction, the scores were higher in the order of PP $(M=6.1, S D=1.01)$, $M S(M=4.8, S D=1.80)$, and TS $(M=3.7, S D=1.68)(M S-T S, P=.032$, PPMS, $\mathrm{p}=.007$, PP-TS, $\mathrm{p}<.001)$.

Table 3: Results of familiarity and overall satisfaction for one-way ANOVA and Tukey HSD tests in drawing task

\begin{tabular}{|c|c|c|c|c|c|}
\hline \multirow{2}{*}{$\begin{array}{l}\text { Dependent } \\
\text { variables }\end{array}$} & \multicolumn{3}{|c|}{ Pen type } & \multirow{2}{*}{$F$} & \multirow{2}{*}{$p$-value } \\
\hline & MS & $T S$ & $P P$ & & \\
\hline \multirow{3}{*}{ Familiarity } & 4.2 & 3.6 & & \multirow{3}{*}{31.16} & \multirow{3}{*}{$<.001$} \\
\hline & 4.2 & & *6.7 & & \\
\hline & & 3.6 & *6.7 & & \\
\hline \multirow{3}{*}{$\begin{array}{l}\text { Overall } \\
\text { satisfaction }\end{array}$} & *4.8 & 3.7 & & \multirow{3}{*}{16.13} & \multirow{3}{*}{$<.001$} \\
\hline & 4.8 & & *6.1 & & \\
\hline & & 3.7 & $* 6.1$ & & \\
\hline
\end{tabular}

Note: For significant $F$ ratios (bold font), * indicates which pen showed significantly higher score.

\subsection{Emotion}

One-way ANOVA and Tukey HSD tests were conducted to analyse emotional variables for each writing and drawing task. The results of the analysis for the writing task are shown in Table 4 . In the case of uncomfortable-comfortable, $P P(M=5.8, S D=1.36), M S(M=4.4, S D=1.76)$, and TS $(M=3.0, S D$ 
$=1.45$ ), in that order, provided more comfortable emotion (PP-MS, $\mathrm{p}=.003$, PP-TS, $\mathrm{p}<.001, \mathrm{MS}$ TS, $p=.004)$. In the case of awkward-natural, PP $(M=6.3, S D=1.00), M S(M=4.2, S D=1.93)$, and TS $(M=3.0, S D=1.73)$, in that order, provided more natural emotion (PP-MS, $p<.001$, PP-TS, $p<$ .001, MS-TS, $p=.022$ ).

TS $(M=3.1, S D=1.50)$ provided softer emotion than PP $(M=4.7, S D=1.77)$ in the case of soft-hard $(p=.002)$. Moreover, TS tended to provide softer emotion than MS $(M=4.1, S D=1.48)(p=.080)$. On the other hand, there was no significant difference between MS and PP $(p=.315)$.

In the case of ordinary-appealing, $T S(M=4.2, S D=1.45)$ and $M S(M=4.8, S D=1.52)$ provided more appealing emotions than PP $(M=1.7, S D=1.11)(p s<.001)$. On the other hand, there was no significant difference between TS and MS $(p=.257)$. In the case of smooth-rough, TS $(M=2.4, S D=$ 1.19) provided smoother emotion than $P P(M=3.6, S D=1.67)(p=.020)$, but there was no significant difference between $M S(M=3.0, S D=1.70)$ and PP $(p=.384)$. In the case of crude-precise, TS $(M=$ $3.5, S D=1.53)$ provided cruder emotion than PP $(M=4.8, S D=1.27)(p=.003)$, but there was no significant difference between $M S(M=4.0, S D=1.48)$ and $P P(p=.120)$.

There were no statistically significant differences among the three pens in the case of thin-thick ( $F$ $=.97, \mathrm{p}=.384)$ and flat-uneven $(\mathrm{F}=1.07, \mathrm{p}=.347)$.

Table 4: Results of emotion variables for one-way ANOVA and Tukey HSD tests in writing task

\begin{tabular}{|c|c|c|c|c|c|}
\hline \multirow{2}{*}{ Dependent variables } & \multicolumn{3}{|c|}{ Pen type } & \multirow{2}{*}{$F$} & \multirow{2}{*}{$p$-value } \\
\hline & MS & $T S$ & $P P$ & & \\
\hline \multirow{3}{*}{$\begin{array}{l}\text { Uncomfortable } \\
\text { - Comfortable }\end{array}$} & *4.4 & 3.0 & & \multirow{3}{*}{22.31} & \multirow{3}{*}{$<.001$} \\
\hline & 4.4 & & *5.8 & & \\
\hline & & 3.0 & *5.8 & & \\
\hline \multirow{3}{*}{$\begin{array}{l}\text { Ordinary } \\
\text { - Appealing }\end{array}$} & 4.8 & 4.2 & & \multirow{3}{*}{40.17} & \multirow{3}{*}{$<.001$} \\
\hline & *4.8 & & 1.7 & & \\
\hline & & $* 4.2$ & 1.7 & & \\
\hline \multirow{3}{*}{$\begin{array}{l}\text { Smooth } \\
\text { - Rough }\end{array}$} & 3.0 & 2.4 & & \multirow{3}{*}{3.77} & \multirow{3}{*}{.027} \\
\hline & 3.0 & & 3.6 & & \\
\hline & & 2.4 & *3.6 & & \\
\hline \multirow{3}{*}{$\begin{array}{l}\text { Thin } \\
\text { - Thick }\end{array}$} & 4.0 & 4.5 & & \multirow{3}{*}{.97} & \multirow{3}{*}{.384} \\
\hline & 4.0 & & 4.0 & & \\
\hline & & 4.5 & 4.0 & & \\
\hline \multirow{3}{*}{$\begin{array}{l}\text { Flat } \\
\text { - Uneven }\end{array}$} & 3.1 & 2.7 & & \multirow{3}{*}{1.07} & \multirow{3}{*}{.347} \\
\hline & 3.1 & & 3.3 & & \\
\hline & & 2.7 & 3.3 & & \\
\hline \multirow{3}{*}{$\begin{array}{l}\text { Soft } \\
\text { - Hard }\end{array}$} & 4.1 & 3.1 & & \multirow{3}{*}{6.45} & \multirow{3}{*}{.003} \\
\hline & 4.1 & & 4.7 & & \\
\hline & & 3.1 & *4.7 & & \\
\hline \multirow{3}{*}{$\begin{array}{l}\text { Crude } \\
\text { - Precise }\end{array}$} & 4.0 & 3.5 & & \multirow{3}{*}{5.91} & \multirow{3}{*}{.004} \\
\hline & 4.0 & & 4.8 & & \\
\hline & & 3.5 & *4.8 & & \\
\hline \multirow{3}{*}{$\begin{array}{l}\text { Awkward } \\
\text { - Natural }\end{array}$} & *4.2 & 3.0 & & \multirow{3}{*}{28.51} & \multirow{3}{*}{$<.001$} \\
\hline & 4.2 & & *6.3 & & \\
\hline & & 3.0 & *6.3 & & \\
\hline
\end{tabular}

Note: For significant $F$ ratios (bold font), * indicates which pen showed significantly higher score.

The results of the analysis for the drawing task are shown in Table 5 . In the case of uncomfortablecomfortable, $\mathrm{PP}(M=6.1, \mathrm{SD}=1.17)$ provided more comfortable emotion than $\mathrm{TS}(M=3.5, \mathrm{SD}=$ $1.85)$ and $M S(M=4.4, S D=1.80)(p s<.001)$. However, $M S$ tended to provide more comfortable feeling than TS $(p=.085)$. In the case of ordinary-appealing, $T S(M=4.3, S D=1.48)$ and $M S(M=$ $5.1, \mathrm{SD}=1.44)$ provided more appealing emotions than PP $(M=2.4, \mathrm{SD}=1.91)(\mathrm{ps}<.001)$. On the 
other hand, there was no significant difference between TS and MS $(p=.162)$. In the case of awkward-natural, $\mathrm{PP}(M=6.2, \mathrm{SD}=1.01)$ provided more natural emotion than $\mathrm{TS}(M=3.2, \mathrm{SD}=1.65)$ and $M S(M=4.0, S D=1.89)(p s<.001)$. On the other hand, there was no significant difference between TS and MS $(p=.140)$.

In the case of smooth-rough, TS $(M=2.4, S D=1.51)$ provided smoother emotion than PP $(M=3.4$, $S D=1.58)(p=.027)$. On the other hand, there was no significant difference between $M S(M=2.8$, $S D=1.73)$ and PP $(p=.275)$. In the case of crude-precise, $T S(M=3.5, S D=1.48)$ provided cruder emotion than PP $(M=4.8, S D=1.25)(p=.005)$. On the other hand, there was no significant difference between MS $(M=4.0, S D=1.89)$ and PP $(p=.103)$.

In the case of hard-soft, TS $(M=2.9, S D=1.48)$ provided softer emotion than $P P(M=4.8, S D=1.85)$. TS also tended to provide softer emotion than $M S(M=4.0, S D=1.78)(p=0.057)$. On the other hand, the difference between MS and PP was not statistically significant $(p=.136)$.

There were no significant differences among the three tools in the case of thin-thick $(F=0.64, p=$ $.536)$ and flat-uneven $(F=1.92, p=.151)$.

Table 5: Results of emotion variables for one-way ANOVA and Tukey HSD tests in drawing task

\begin{tabular}{|c|c|c|c|c|c|}
\hline \multirow{2}{*}{ Dependent variables } & \multicolumn{3}{|c|}{ Pen type } & \multirow{2}{*}{$F$} & \multirow{2}{*}{$p$-value } \\
\hline & MS & $T S$ & $P P$ & & \\
\hline \multirow{3}{*}{$\begin{array}{l}\text { Uncomfortable } \\
\text { - Comfortable }\end{array}$} & 4.4 & 3.5 & & \multirow{3}{*}{17.28} & \multirow{3}{*}{$<.001$} \\
\hline & 4.4 & & *6.1 & & \\
\hline & & 3.5 & *6.1 & & \\
\hline \multirow{3}{*}{$\begin{array}{l}\text { Ordinary } \\
\text { - Appealing }\end{array}$} & 5.1 & 4.3 & & \multirow{3}{*}{19.13} & \multirow{3}{*}{$<.001$} \\
\hline & *5.1 & & 2.4 & & \\
\hline & & $* 4.3$ & 2.4 & & \\
\hline \multirow{3}{*}{$\begin{array}{l}\text { Smooth } \\
\text { - Rough }\end{array}$} & 2.8 & 2.4 & & \multirow{3}{*}{3.51} & \multirow{3}{*}{.035} \\
\hline & 2.8 & & 3.4 & & \\
\hline & & 2.4 & *3.4 & & \\
\hline \multirow{3}{*}{$\begin{array}{l}\text { Thin } \\
\text { - Thick }\end{array}$} & 3.5 & 4.1 & & \multirow{3}{*}{1.08} & \multirow{3}{*}{.345} \\
\hline & 3.5 & & 3.7 & & \\
\hline & & 4.1 & 3.7 & & \\
\hline \multirow{3}{*}{$\begin{array}{l}\text { Flat } \\
\text { - Uneven }\end{array}$} & 3.4 & 2.6 & & \multirow{3}{*}{1.60} & \multirow{3}{*}{.210} \\
\hline & 3.4 & & 3.1 & & \\
\hline & & 2.6 & 3.1 & & \\
\hline \multirow{3}{*}{$\begin{array}{l}\text { Soft } \\
\text { - Hard }\end{array}$} & 4.0 & 2.9 & & \multirow{3}{*}{9.14} & \multirow{3}{*}{$<.001$} \\
\hline & 4.0 & & 4.8 & & \\
\hline & & 2.9 & $* 4.8$ & & \\
\hline \multirow{3}{*}{$\begin{array}{l}\text { Crude } \\
\text { - Precise }\end{array}$} & 4.0 & 3.5 & & \multirow{3}{*}{5.39} & \multirow{3}{*}{.006} \\
\hline & 4.0 & & 4.8 & & \\
\hline & & 3.5 & $* 4.8$ & & \\
\hline \multirow{3}{*}{$\begin{array}{l}\text { Awkward } \\
\text { - Natural }\end{array}$} & 4.0 & 3.2 & & \multirow{3}{*}{26.01} & \multirow{3}{*}{$<.001$} \\
\hline & 4.0 & & *6.2 & & \\
\hline & & 3.2 & *6.2 & & \\
\hline
\end{tabular}

Note: For significant $F$ ratios (bold font), ${ }^{*}$ indicates which pen showed significantly higher score.

\section{5}

\section{DISCUSSION}

The stylus providing texture was not effective in respect of task completion time and error amount. The hypothesis that it will help achieve a better performance effect in drawing tasks was not supported. It seems that it is difficult to improve performance by merely providing pen-and-paper texture, since the stylus products are sufficiently developed in their functional aspects. Moreover, 
the Wacom stylus pen used in the experiment had excellent pressure sensitivity and little input delay.

On the other hand, there were significant differences in respect of familiarity and overall satisfaction, which were subjective measures of usability variables. For all tasks, PP received the highest rating. Even if a tactile texture is provided by a stylus, it is still difficult to achieve a subjective experience that corresponds to that provided by an analogue pen and paper. However, MS received better evaluation than TS. Specifically, MS received better evaluation than TS for familiarity in the writing task. Users who are familiar with writing with an analogue pen and paper evaluated the familiarity of the stylus pen providing pen-and-paper texture higher than that of the typical stylus pen. This is similar to the findings of previous research that reports that providing user-friendly pen-like texture through a stylus using electrical vibrations leads to improved handwriting [17]. In the drawing task, MS provided higher overall satisfaction than TS. These are in line with the hypothesis that MS will help achieve increased user satisfaction in writing and drawing.

The analysis of emotional variables showed that the results for the writing and drawing tasks were similar. First, in uncomfortable-comfortable, comfort was provided in the order of PP, MS, and TS, and the difference among the three tools was statistically significant. Participants felt most comfortable with the analogue pen-and-paper environment, which they normally use. They felt more comfortable with MS, which provides a texture similar to an analogue pen, than with a typical stylus.

In the case of ordinary-appealing, there was no difference between the existence and the nonexistence of the pen-and-paper texture. However, there was a difference in emotion between the analogue pen and the stylus. Compared with the stylus pen, the analogue pen and paper felt more ordinary. This is probably because the analogue pen and paper are the most basic tools for writing. However, the reason that the stylus pen providing texture did not feel as ordinary as the analogue pen and paper is that the tablet on which the handwriting was written, and the monitor on which the writing was displayed, were separate.

Regarding the analysis of smooth-rough, soft-hard, and crude-precise, the typical stylus pen did not provide the emotion of the analogue pen and paper. However, the stylus pen providing texture provided similar emotion compared with the analogue pen and paper. Compared with the typical stylus pen, the analogue pen and paper was found to be rougher, harder, and more precise. In other words, when using the stylus pen providing pen-and-paper texture, the emotions experienced with the analogue pen and paper are felt more than those experienced with the typical stylus pen.

Regarding the analysis of awkward-natural, PP provided more natural emotions than MS and TS in all tasks. In the writing task, MS provided more natural emotion than TS, but there was no difference between MS and TS in the drawing task. The drawing task is relatively more complicated than the writing task, so it is difficult to overcome the awkwardness of a common stylus pen simply by using a stylus providing a texture similar to that of an analogue pen. These results are consistent with those of Poupyrev, Okabe, and Maruyama [18]. The stylus providing texture was well-evaluated in terms of usability and subjective preference in the drawing task, but it did not provide the feel of an analogue pen and paper.

There were no differences among the three tools in the case of thin-thick and flat-uneven. These seem to be adequately provided by typical stylus pens.

\section{CONCLUSION}

This study investigated the change in user experience when using a stylus pen providing the texture of pen and paper. It attempted to examine the directions that should be taken to improve the experience of using stylus pens by comparing a stylus pen providing texture, a typical stylus pen, and an analogue pen and paper. Regarding task completion time and error amount, which are performance measures of usability variables, the stylus pen providing texture did not show a significant difference from the typical stylus pen. On the other hand, regarding familiarity and overall satisfaction, which are subjective measures of usability variables, improvement in the existing stylus was achieved by the stylus providing a texture similar to an analogue pen. 
The emotions felt when using an analogue pen and paper differed markedly from those felt when using a common stylus that does not provide texture. In particular, the analogue pen and paper, the most commonly used writing instrument in everyday life, was more comfortable and natural. On the other hand, using a common stylus that does not provide texture felt uncomfortable and awkward. In this case, when a stylus is made that is capable of providing a texture similar to an analogue pen, user emotions are closer to those felt in an actual analogue pen environment.

This study confirmed the change in user experience brought about by using a stylus pen providing the texture of pen and paper. Directions for the further development of usability and emotional aspects were also confirmed through comparison with an analogue pen-and-paper environment. First, we found that efforts to provide texture through a stylus pen do not help improve its quantitative usability. Therefore, further technical research should be conducted to increase the quantitative usability of stylus pens. However, improvements in familiarity and user satisfaction achieved through stylus pens that provide texture are worthwhile, and making stylus pens capable of providing emotions similar to those experienced when using an analogue pen and paper is also an important factor that can make stylus pens more attractive to users.

In this study, a graphic tablet was used as an experimental tool. Its characteristic is that the surface on which the stylus pen is used is separated from the monitor device on which the output appears. This has the limitation of not properly representing a tablet PC or smart mobile device, where the portion on which the stylus pen is used and the display portion that produces the output are same. This may have affected some user emotions. Therefore, it is necessary to review the results of this study by conducting future studies on the use of textures using tablet PCs or smart mobile devices that have no such limitation. Although this study did not develop a stylus and tablet that provide a texture similar to that of an analogue pen and paper, it is still meaningful because it showed that user experience can be improved through the use of a stylus pen providing texture, and confirmed the necessity of the development of such stylus pens.

\section{ACKNOWLEDGEMENTS}

This work was partially supported by the National Research Foundation of Korea (NRF) grant funded by the Korea government (MSIT) (No. 2018R1C1B6004459).

\section{REFERENCES}

[1] Smith, B.A. \& Zhai, S. 2001. Optimised virtual keyboards with and without alphabetical ordering - A novice user study. In Proceedings of INTERACT, 92-99.

[2] Zhai, S. \& Smith, B.A. 2001. Alphabetically biased virtual keyboards are easier to use: Layout does matter. In Conference on Human Factors in Computing Systems, 321-322. doi:10.1145/634067.634257.

[3] Ko, C. 2015. Ubiquitous computing application and wireless sensor. Ubiquitous Comput. Appl. Wirel. Sens., 331, 385-391. doi:10.1007/978-94-017-9618-7.

[4] Universal Stylus Initiative. 2015. Universal stylus initiative launched to create a specification for an active stylus. Available online: https://universalstylus.org/news-events/usi-launched (accessed on 01-10-2018).

[5] Harley, J.A., Tan, L., Mukherjee, D. \& Hotelling, S.P. 2014. Stylus orientation detection. U.S. Patent No. 8,638,320, Washington, DC: U.S. Patent and Trademark Office.

[6] Annett, M.K. 2014. The fundamental issues of pen-based interaction with tablet devices. University of Alberta, Edmonton, Alberta, Canada. Doctoral Dissertation. doi:10.7939/R3Q23R65D.

[7] Annett, M., Anderson, F., Bischof, W.F. \& Gupth, A. 2014. The pen is mightier: Understanding stylus behaviour while inking on tablets. In Proceedings of the 2014 Graphics Interface Conference, 193-200.

[8] Lin, C.L., Li, C.S., Chang, Y.M., Lin, T.C., Chen, J.F. \& Lin, U.C. 2013. Pressure sensitive stylus and algorithm for touchscreen panel. J. Disp. Technol., 9, 17-23. doi:10.1109/JDT.2012.2220524.

[9] Henzen, A., Ailenei, N., van Reeth, F., Vansichem, G., Zehner, R.W. \& Amundson, K. 2004. 32.4: An electronic ink low latency drawing tablet. SID Symp. Dig. Tech. Pap., 35(1), 1070-1073. doi:10.1889/1.1825712.

[10] Ng, A., Annett, M., Dietz, P., Gupta, A. \& Bischof, W.F. 2014. In the blink of an eye: Investigating latency perception during stylus interaction. In Proceedings of the 32nd Annual ACM Conference on Human Factors in Computing Systems, 1103-1112. doi:10.1007/3-7643-7385-7_17.

[11] Annett, M. \& Bischof, W.F. 2015. Hands, hover, and nibs: Understanding stylus accuracy on tablets. In Proceedings of the 41st Graphics Interface Conference, 203-210.

[12] Zitnick, C.L. 2013. Handwriting beautification using token means. ACM Trans. Graph., 32(4), 53. doi:10.1145/2461912.2461985.

[13] Orbay, G. \& Kara, L.B. 2011. Beautification of design sketches using trainable stroke clustering and curve fitting. IEEE Trans. Vis. Comput. Graph., 17(5), 694-708. doi:10.1109/TVCG.2010.105. 
[14] Ren, X., Wang, Q. \& Sun, X. 2016. EV-Pen : An electrovibration haptic feedback pen for touchscreens. In SIGGRAPH ASIA 2016 Emerging Technologies, 8. doi:10.1145/2988240.2988241.

[15] Wang, Q., Ren, X. \& Sun, X. 2017. Enhancing pen-based interaction using electrovibration and vibration haptic feedback. In Proceedings of the 2017 CHI Conference on Human Factors in Computing Systems, 3746-3750. doi:10.1145/3025453.3025555.

[16] Boscaglia, N.S., Gaudio, L.A. \& Ribeiro, M.R.N. 2011. A low cost prototype for an optical and haptic pen. In 2011 ISSNIP Biosignals and Biorobotics Conference, 71-74. doi:10.1109/BRC.2011.5740660.

[17] Wang, Q., Ren, X., Sarcar, S. \& Sun, X. 2016. EV-Pen: Leveraging electrovibration haptic feedback in pen interaction. In Proceedings of the 2016 ACM on Interactive Surfaces and Spaces, 57-66. doi:10.1145/2992154.2992161.

[18] Poupyrev, I., Okabe, M. \& Maruyama, S. 2004. Haptic feedback for pen computing: directions and strategies. In CHI'04, Vienna, 1309-1312. doi:10.1145/985921.986051.

[19] Kyung, K. \& Lee, J. 2008. wUbi-Pen: Windows graphical user interface interacting with haptic feedback stylus. In ACM SIGGRAPH 2008 New Tech Demos, 21, 142-155. doi:10.1145/1401615.1401657.

[20] Kuchenbecker, K.J., McMahan, W., Landin, N. \& Romano, J.M. 2010. Dimensional reduction of highfrequency accelerations for haptic renderin, In International conference on human haptic sensing and touch enabled computer applications. Springer, Berlin, Heidelberg. 79-86, doi:10.1007/978-3-642-14075-4.

[21] Romano, J.M. \& Kuchenbecker, K.J. 2012. Creating realistic virtual textures from contact acceleration data. IEEE Trans. Haptics, 5, 109-119. doi:10.1109/TOH.2011.38.

[22] Xin, Y., Bi, X. \& Ren, X. 2012. Natural use profiles for the pen: An empirical exploration of pressure, tilt, and azimuth. In Proceedings of the 2012 ACM annual conference on Human Factors in Computing Systems - CHI '12, 801-804. doi:10.1145/2207676.2208518.

[23] Hale, K.S. \& Stanney, K.M. 2004. Deriving haptic design guidelines from human physiological, psychophysical, and neurological foundations. IEEE computer graphics and applications, 24(2), 33-39.

[24] Picard, D., Dacremont, C., Valentin, D. \& Giboreau, A. 2003. Perceptual dimensions of tactile textures. Acta Psychol. (Amst)., 114, 165-184. doi:10.1016/j.actpsy.2003.08.001.

[25] Park, E., Del Pobil, A.P. \& Kwon, S.J. 2015. Usability of the stylus pen in mobile electronic documentation. Electronics, 4, 922-932, doi:10.3390/electronics4040922.

[26] Ahn, J., Kim, K., Proctor, R. \& Salvendy, G. 2019. Emotional factors and physical properties of pen affecting user satisfaction. Appl. Ergon (submitted). 